\title{
La rebelión de las ruanas: el paro nacional agrario en Colombia*
}

\author{
Edwin Cruz Rodríguez
}

Recibido: 12 de agosto de 2016 - Aprobado: 4 de septiembre de 2016

\section{Resumen}

Este trabajo analiza el origen y desarrollo del paro agrario de 2013, con base en el enfoque para el estudio de los movimientos sociales conocido como la "agenda clásica". Si bien la crisis del sector agrario puede concebirse un desencadenante de la protesta, su magnitud y alcance no hubiera sido posible sin el respaldo de procesos organizativos como Dignidad Agropecuaria, la Mesa Agraria y Popular de Interlocución y Acuerdo y el Coordinador Nacional Agrario, los cuales aprovecharon las oportunidades políticas, articularon a su causa distintos actores sociales y políticos, y disputaron la construcción del sentido sobre los problemas del sector agrario. En la primera parte, se reconstruye la contienda política en la que se enmarca el paro agrario; en la segunda, se analizan las oportunidades políticas de la coyuntura, las estructuras de movilización y los marcos de acción colectiva.

Palabras clave: Colombia, campesinos, paro agrario 2013, protesta social.

Artículo de reflexión. Investigación personal del autor que hace parte del seguimiento a la protesta social en Colombia. DOI: http://dx.doi.org/10.15332/s0120-8454.2016.0090.04

Candidato a doctor en Estudios Políticos de la Universidad Nacional de Colombia. Profesor ocasional del Departamento de Ciencia Política en la misma Institución. Correo electrónico: ecruzr@unal.edu.co 


\section{The rebellion of the ruanas. The agricultural strike in Colombia*}

Edwin Cruz Rodríguez

\section{Abstract}

This paper analyzes the origin and development of the agricultural strike of 2013, based on the study of social movements known as the "classic agenda". The crisis in the agricultural sector can be seen as a trigger for the protest. However, their size and scope would not have been possible without the support of organizational processes as Dignidad Agropecuaria, Mesa Agraria y Popular de Interlocución y Acuerdo and Coordinador Nacional Agrario. Such processes took advantage of political opportunities, articulated their cause with different social and political actors, and disputed the meaning-building mechanisms about the problems of the agricultural sector. In the first part, the political contest that frames the agricultural strike is reconstructed; in the second part, political opportunities, mobilization structures and collective frameworks are analyzed.

Keywords: Colombia, peasants, agricultural strike 2013, social protest.

Reflection article. Personal research of the author who is part of the follow-up to the social protest in Colombia.DOI: http://dx.doi.org/10.15332/s0120-8454.2017.0090.04

** PhD candidate in Political Studies of the National University of Colombia. Occasional Professor of the Department of Political Science at the same Institution. Email: ecruzr@unal.edu.co 


\section{La révolte des ruanas: grève nationale agricole en Colombie*}

Edwin Cruz Rodríguez

\section{Résumé}

Ce travail analyse l'origine et le développement de la grève agraire de 2013, basé sur l'étude des mouvements sociaux connu comme l' "agenda classique". Bien que la crise du secteur agricole peut se concevoir comme un déclencheur de la protestation, sa grandeur et sa portée n'aurait pas été possible sans le soutien de processus organisationnels comme Dignité Agricole (Dignidad Agropecuaria), Groupe Agraire (Mesa Agraria) et Populaire d'Interlocution et Accord (Popular de Interlocución y Acuerdo) et le Coordinateur National Agricole, lesquels ont saisi les opportunités politiques et ont articulés en leur faveur différents acteurs sociaux et politiques, et ont disputé la construction du sens sur les problèmes du secteur agricole. Dans la première partie, on reconstruit le contexte politique dans lequel se développe cette grève du secteur agricole; dans la deuxième partie, on analyse les opportunités politiques de cette conjoncture, les structures de mobilisation et les cadres d'action collective.

Mots clés: Colombie, paysans, grève agraire 2013, protestation sociale.

Article de réflexion. Recherche personnelle de l'auteur qui fait partie d'un suivi à cette protestation sociale en Colombie DOI: http://dx.doi.org/10.15332/s0120-8454.2017.0090.04

Candidat à docteur en Études Politiques de I’Université Nationale de Colombie. Professeur occasionnel du Département de Science Politique de la même institution. Email: ecruzr@unal.edu.co 


\section{Introducción}

Entre el 19 de agosto y el 12 de septiembre de 2013 tuvo lugar la protesta agraria más importante de las últimas décadas en Colombia. La mayor parte del territorio nacional se vio afectada por bloqueos, mítines, marchas, cacerolazos y otros repertorios de protesta. Según estimaciones de los convocantes, participaron más de 200.000 personas (El Espectador, 2013a). La afectación de la movilidad produjo el desabastecimiento de productos de primera necesidad en las ciudades, el incremento de sus precios y enormes pérdidas económicas para distintos sectores. ¿Cuáles son los factores que explican el origen y desarrollo de esta movilización social?

Los actores sociales tienden a explicar esta excepcional acción colectiva por la gravedad de la situación que enfrentan los pequeños y medianos productores agrarios, principalmente los altos precios de los insumos agrícolas, el ingreso al país de productos extranjeros debido a los tratados de libre comercio y al contrabando, las dificultades de acceso al crédito y a la propiedad territorial, entre otras (Duzán, 2014, p. 13). Sin embargo, estos factores son necesarios pero no suficientes para explicar la protesta, puesto que en otras circunstancias ha habido crisis agraria, e incluso muchos de los problemas del sector son estructurales, y aún así no se había presentado una protesta de esta magnitud.

Este trabajo analiza el origen y desarrollo del paro agrario con base en el enfoque para el estudio de los movimientos sociales conocido como la "agenda clásica" (McAdam, Tarrow y Tilly, 2005, p. 45; McAdam, McCarthy y Zald, 1999; Tarrow, 1997). Esta perspectiva es una síntesis analítica que permite estudiar los movimientos sociales de forma integral. Así, no reduce la explicación de la acción colectiva a una sola variable, ya se trate de las tensiones estructurales (Smelser, 1995), la racionalidad económica de los actores (Olson, 1992) o la construcción de la identidad colectiva (Melucci, 1999; Touraine, 1987). Por el contrario, recoge estos factores y los articula en un esquema analítico que vincula la dimensión estructural con el concepto de estructura de oportunidad politica (EOP), el cual hace referencia a las características catalizadoras del contexto en el que se desarrollan los movimientos, pero también las dimensiones subjetivas de la acción colectiva: la organización, mediante la categoría de estructuras de movilización, y la construcción de sentido, con el concepto de marcos de la acción colectiva.

La crisis del sector agrario puede concebirse un desencadenante de la protesta. Sin embargo, su magnitud y alcance no hubiera sido posible sin el soporte de procesos organizativos como Dignidad Agropecuaria, la Mesa Agraria y Popular de Interlocución y Acuerdo (MIA) y el Coordinador Nacional Agrario (CNA), los cuales aprovecharon las oportunidades políticas, articularon a su causa distintos actores sociales y políticos, y disputaron la construcción del sentido sobre los problemas del sector agrario. 
En la primera parte, se reconstruye la contienda política en la que se enmarca el paro agrario. En la segunda se analizan las oportunidades políticas de la coyuntura, las estructuras de movilización y los marcos de acción colectiva.

\section{La contienda política}

Siguiendo a McAdam, Tarrow y Tilly (2005, p. 5), la contienda política es "la interacción episódica, pública y colectiva entre los reivindicadores y sus objetos cuando: 1) al menos un gobierno es uno de los reivindicadores y 2) las reivindicaciones, caso de ser satisfechas, afectarían a los intereses de al menos uno de los reivindicadores". Esta categoría permite eliminar las fronteras analíticas entre la política no institucionalizada (contienda transgresiva) y la institucionalizada (contienda contenida), para comprender los episodios de protesta en un marco holístico que destaca sus relaciones con la política convencional.

La contienda política en la que se enmarca el paro nacional agrario está compuesta por dos momentos. En el primero, salen a flote las divisiones entre los promotores de la protesta, mientras el Gobierno intenta reducir su magnitud. En el segundo, a partir de las declaraciones del presidente Santos en las que niega la existencia del paro, hay un apoyo inusitado a la protesta en las ciudades, pero al mismo tiempo la estrategia gubernamental de entablar negociaciones fragmentadas rinde frutos.

\section{La protesta toma fuerza}

Las organizaciones campesinas empezaron el paro divididas y presentaron tres pliegos de peticiones, lo que restó fuerza al inicio de la protesta. El Gobierno puso en práctica cuatro estrategias: atender el paro por sectores evitando la conformación de una mesa única, reprimir los bloqueos de vías públicas, una campaña de declaraciones para reducir la importancia de las movilizaciones y el condicionamiento de la negociación al cese del paro.

El 20 y 21 de julio se reunieron delegados de distintas organizaciones campesinas en Neiva (Huila) para ultimar los detalles del paro convocado para el 19 de agosto. Asistieron representantes 27 departamentos y oficiaron como presidentes Piedad Córdoba, de Marcha Patriótica, y Huber Ballesteros, de la Federación Nacional Sindical Unitaria Agropecuaria (Fensuagro). La reunión concluyó que la situación del agro era extremadamente delicada, puesto que el Gobierno no había cumplido los acuerdos a que llegó con los caficultores tras el paro del mes de marzo, la "locomotora minera" había generado un notorio deterioro ambiental en varios lugares del país y había distintos sectores amenazados por el tratado de libre comercio de la Alianza Pacífico, que redundaría en mayores importaciones de productos nacionales como café, arroz y papa (Prensa Rural, 2013a). 
Algunas organizaciones, en particular la Mesa Agropecuaria y Popular de Interlocución y Acuerdo (MIA), se inclinaban por la apertura de una mesa de negociación nacional, al considerar que los problemas no eran de uno u otro sector, sino que necesitaban una respuesta estructural de política agraria. Sin embargo, no se consiguió hacer una convocatoria unificada al paro, de tal manera que las organizaciones campesinas produjeron tres pliegos, de Dignidad Agropecuaria, de la MIA y del CNA. A principios de agosto, al paro se sumaron sectores sindicales, encabezados por la Central Unitaria de Trabajadores, y sindicatos del sector salud.

La primera respuesta del Gobierno frente al paro fue el anuncio de la represión. Con base en la Ley 1453 de 2011, o de "seguridad ciudadana", el ministro del Interior, Fernando Carrillo, instó a los mandatarios locales a no permitir los bloqueos de vías públicas. Así mismo, declaró que no se negociaría en medio del paro (El Tiempo, 2013a). El Gobierno también intentó neutralizar la convocatoria lanzada por los cafeteros, pensando que era el eje articulador de la protesta. Por eso, el vicepresidente, Angelino Garzón, y el ministro de Agricultura, Francisco Estupiñán, se reunieron durante cuatro horas con los representantes de Dignidad Cafetera, organización de pequeños y medianos caficultores responsable del paro de principios de año. Así mismo, el presidente Santos se reunió con los caficultores del Huila, el departamento con mayor producción del grano. Aunque estos últimos dudaron en entrar a la protesta en época de cosecha, el Gobierno no consiguió desactivar la convocatoria. Óscar Gutiérrez, líder de Dignidad Cafetera, sostuvo que el Gobierno no hacía lo suficiente para resolver los problemas de fondo y más bien, trataba de dividir el movimiento (Bermúdez, 2013).

Para los campesinos de Dignidad Agropecuaria la principal razón para protestar era el incumplimiento del Gobierno con los acuerdos a que habían llegado tras las protestas de noviembre de 2011 y mayo de 2013 (El Tiempo, 2013b). Las reivindicaciones comprendían una política agraria para resolver los problemas estructurales del sector, reducir los precios de los insumos agrícolas, detener las importaciones de productos nacionales, suspender los tratados de libre comercio, condonar las deudas de los productores, establecer precios de sustentación para productos nacionales e impedir la extranjerización de la propiedad territorial.

El primer día del paro, las movilizaciones no fueron muy nutridas, debido a la división entre los convocantes, aunque hubo acciones colectivas en 30 de los 32 departamentos del país (Prensa Rural, 2013b), bloqueos en Boyacá, Arauca, Putumayo y Nariño, y enfrentamientos entre manifestantes y Policía en distintos lugares. En el Eje Cafetero, Santander, Caquetá, Magdalena Medio y la Costa Atlántica hubo manifestaciones sin bloqueos. Al final de la jornada, la Policía reportó 31 capturas (El Tiempo, 2013c).

Además de la represión, el Gobierno intentó reducir el alcance de la movilización, acentuar la división de los manifestantes y condicionar una negociación al levantamiento del paro. El ministro de Agricultura, Francisco Estupiñán, 
declaró que el Gobierno no accedería a negociar bajo presión y que además no era necesaria la mesa nacional, puesto que el Gobierno tenía varias mesas abiertas con los distintos sectores (El Espectador, 2013b).

De esa manera, el Gobierno había conseguido bajarle el alcance a la protesta, pero no esperaba su fuerza en Nariño, Boyacá, Cauca, Arauca y Putumayo, donde se realizaron grandes bloqueos. La vía Panamericana estaba intransitable entre Cali y Pasto, debido a protestas de campesinos y pueblos indígenas. El 21 de agosto, según el gobernador de Boyacá, Juan Carlos Granados, la protesta se había salido de control, debido a enfrentamientos entre manifestantes y policías en prácticamente todo el departamento, no había ingreso ni salida por vía terrestre (El Tiempo, 2013d). Ese mismo día se produjo un enfrentamiento entre manifestantes de Ubaté (Cundinamarca) y policías, que dejó heridos cinco manifestantes y a diez policías (El Espectador, 2013c). También hubo protestas en las universidades públicas en Bogotá.

Al tercer día del paro, a los bloqueos se sumó el desabastecimiento de alimentos en las principales ciudades y el incremento en su precio. Además, las cosechas de café y arroz, así como los productos lácteos perecederos, se verían afectados si no se resolvía con prontitud la protesta (El Espectador, 2013d). El partido liberal empezó a ejercer presión sobre el Gobierno al pedir la renuncia de Francisco Estupiñán como ministro de Agricultura (El Espectador, 2013e).

El 22 de agosto se presentaron graves enfrentamientos entre manifestantes y policías en la ciudad de Duitama, donde se declaró el toque de queda debido a los saqueos del comercio y el apedreamiento de la alcaldía. En Zipaquirá también hubo grandes enfrentamientos por más de cinco horas, que dejaron veinticinco personas detenidas, seis heridos y varios vehículos averiados ( $E l$ Tiempo, 2013e). Los cafeteros del Huila anunciaron que entrarían en paro el 24 de agosto, decisión que se producía por la presión de las bases sociales en el departamento (La Silla Vacía, 2013a).

Al día siguiente había 37 bloqueos en 9 departamentos y las protestas cada vez se acercaban más a Bogotá, pues en Usme se inició un bloqueo (Semana, 2013a). El Gobierno empezó a enfrentar presiones de otros actores. Por ejemplo, la Federación Nacional de Arroceros (Fedearroz), señaló los efectos negativos del paro en los departamentos de Arauca, Casanare y Meta, en donde de una cosecha de 800.000 toneladas, por las dificultades de transporte y de aprovisionamiento de combustible, aún falta por recolectar 500.000 (El Espectador, 2013f). Jordi Raich, jefe del CICR en Colombia llamó la atención sobre el desabastecimiento en los hospitales y 28 agresiones a la misión médica durante el paro (El Espectador, 2013g).

El Gobierno continuó con su estrategia de fragmentar las mesas de negociación por sectores y envió comisiones a Boyacá y Meta para empezar diálogos con los líderes de la protesta (El Tiempo, 2013f). El 24 de agosto, el ministro de Agricultura viajo a Tunja junto con una delegación en la que participaba 
el secretario de la Presidencia, Aurelio Iragorri, mientras el viceministro fue a Villavicencio junto con una comisión del Ministerio del Interior.

\section{El tal paro agrario sí existe}

La aparente debilidad de la manifestación daría un giro radical tras las declaraciones del presidente Santos, quien, para aminorar la importancia de la protesta, dijo: "Ese tal paro nacional agrario no existe" (El Espectador, 2013h), puesto que generó un sentimiento de indignación que, aunado a las imágenes de la represión, llevarían a la vinculación de los pobladores de las ciudades con la protesta.

En efecto, se empezaron a conocer videos en las redes sociales de policías agrediendo a los campesinos manifestantes en varias regiones del país, robando comida y víveres, destruyendo campamentos e ingresando a sus viviendas sin orden judicial (El Espectador, 2013i). El rechazo a este comportamiento motivó los cacerolazos, un repertorio de acción que empezó a tomar forma en las principales ciudades del país. Las convocatorias a estas acciones se hicieron por redes sociales y posicionaron la ruana como el símbolo de solidaridad con el campesinado por parte de los habitantes de las urbes. Los cacerolazos fueron el pan de cada día a partir del 26 de agosto. En Tunja, cerca de 50.000 personas se congregaron en la Plaza de Bolívar (El Tiempo, 2013g). La misma forma de protesta se realizó en Bogotá y se repetiría en otras ciudades. El mismo día se produjeron disturbios y saqueos en las poblaciones de Facatativá, Ubaté y Zipaquirá. Ya se registraba un alza en el precio de los alimentos de más de un cien por ciento a causa del paro (El Tiempo, 2013h).

El avance del paro campesino se observa en que el Gobierno tuvo que ceder y negociar en medio de los bloqueos ante el sector de Dignidad Agropecuaria, en la Mesa Intersectorial Agropecuaria, incluso el mismo presidente acudió a establecer los diálogos. Santos viajó a Tunja y acordó una mesa de negociación con algunos voceros de los campesinos de Boyacá, Cundinamarca y Nariño, que se instalaría al día siguiente. El costo que la protesta empezaba a adquirir para el Gobierno puede evidenciarse en el hecho de que ministro de Agricultura ofreció su cargo si con eso se solucionaba la crisis, luego de que Santos afirmara que era inaceptable incumplir los compromisos con los campesinos (El Espectador, 2013j).

La mesa de negociación inició en Tunja el 27 de agosto, con participación de los ministros de Agricultura, Francisco Estupiñán, y de Interior, Fernando Carrillo, y del secretario general de la presidencia, Aurelio Iragorri. En las ciudades seguía creciendo el apoyo al paro campesino, mediante cacerolazos. En Bogotá, el alcalde Gustavo Petro suspendió las clases oficiales el 28 de agosto. En la noche se produjeron disturbios en varias zonas que obligaron a decretar el toque de queda en la localidad de Ciudad Bolívar (El Espectador, 2013k). 
Las negociaciones dejaban por fuera a la MIA y al CNA, por lo que para el 29 de agosto se promovió una movilización en distintas ciudades del país con el fin de hacerle saber al Gobierno que debía negociar con todos los manifestantes. Según Andrés Gil, de la Marcha Patriótica, el Gobierno quería hacer creer que negociando con parte de los campesinos de Boyacá, Nariño y Cundinamarca, iba a terminar con el problema, se trataba de visibilizar las problemáticas de los demás sectores en paro y obligarlo a que reconociera la legitimidad de la MIA, que demandaba una mesa única con el Gobierno (Prensa Rural, 2013c).

Durante esa manifestación se produjeron grandes enfrentamientos con la Policía en ciudades como Bogotá y Medellín. En Soacha se bloqueó la autopista sur durante todo el día y, ante la magnitud de los disturbios, el alcalde de Bogotá, Gustavo Petro, también decretó toque de queda en las localidades de Bosa, Suba y Engativá, en cada una de las cuales hubo un asesinato durante los enfrentamientos (Semana, 2013b). Al final de la jornada, quedaron 5 muertos y más de 200 heridos, el Gobierno diferenció a los manifestantes pacíficos de los "vándalos" que según él infiltraban las protestas (El Tiempo, 2013i). Al día siguiente el ministro de Defensa, Juan Carlos Pinzón, acusó a las Farc de estar detrás de todos los bloqueos y desmanes en el paro (El Tiempo, 2013j). Santos ordenó la militarización de varias ciudades, entre ellas Bogotá (Semana, 2013c).

Pese a la fuerza que tomó la protesta en las ciudades, la estrategia gubernamental de negociar en mesas fragmentadas empezó a rendir sus frutos, de forma que en los días siguientes se empezaron a sellar acuerdos para levantar los bloqueos e iniciar negociaciones. El 1.ำ de septiembre, el ministro de Interior, Fernando Carrillo, consiguió un acuerdo con 25 gobernadores de los pueblos indígenas Pastos y Quillacinga, que terminó con los bloqueos en Nariño. El acuerdo se basaba en la expedición de un documento Conpes para el sector agrario del departamento y la instalación de una mesa de trabajo el 17 de septiembre, para hablar sobre la propiedad de la tierra, la infraestructura vial, la salud, la justicia, los derechos humanos y el desarrollo agropecuario (Semana, 2013d).

A 16 días del paro aún había bloqueos en siete departamentos: Antioquia, Valle, Cauca, Huila, Nariño, Caquetá y Putumayo (El Espectador, 20131). No obstante, el Gobierno avanzaba en acuerdos sectoriales y el 3 de septiembre consiguió uno con las Organizaciones Cívicas y Populares de Arauca para el levantamiento inmediato del paro. Allí se instalaría una mesa de trabajo a partir del 5 de septiembre en la que participarían representantes de los gobiernos local y nacional además de delegados de las organizaciones (El Espectador, 2013m).

El 5 de septiembre, tras 20 días de protestas, el secretario de la Presidencia, Aurelio Iragorri, y los voceros de la Mesa Sectorial Agropecuaria de Nariño, Boyacá y Cundinamarca convinieron no aplicar la Resolución 970 de 2010 sobre semillas certificadas y trabajar al respecto en una mesa con los delegados campesinos. No obstante, no se llegó a un acuerdo sobre la renegociación de los TLC con EE. UU. y la U. E. Como alternativa, el Gobierno propuso compensaciones por la entrada al país de papa precocida y leche en polvo, artículos 
que se asumirían como si hubiesen sido producidos en el país y se les pagaría a los productores el precio doméstico por cada tonelada importada durante dos años. Asimismo, se prohibiría la rehidratación de leche en polvo importada para distribuirla en el país como leche líquida (El Espectador, 2013n).

Un día después, los ministros de Interior y Agricultura acordaron con los líderes campesinos del Huila el levantamiento del paro. El acuerdo contemplaba la presentación de un proyecto de ley para condonar las deudas a los campesinos hasta por 20 millones con una fecha de corte a 31 de diciembre de 2012; la oficialización del subsidio cafetero o Protección del Ingreso Cafetero hasta fines de 2014; el estudio de mecanismos para subsidiar insumos y fertilizantes; la lucha contra el contrabando y la revisión de la institucionalidad estatal del sector agropecuario para promover la protección de la producción nacional ( $E l$ Espectador, 2013o).

Finalmente, el 7 de septiembre, el vicepresidente Angelino Garzón se reunió con 29 dirigentes campesinos de la MIA y los gobernadores de los departamentos de Cauca, Nariño, Putumayo, Tolima, Huila, Meta y Caquetá, en Popayán, para desactivar el paro. Tras un día de diálogos se alcanzó un acuerdo mediante el cual el Gobierno se comprometía a crear salvaguardias par la importación de productos agropecuarios de países con los que Colombia tuviese acuerdos comerciales y constituir una comisión de alto nivel para negociar el pliego de peticiones de la MIA, entre otros. Los voceros de la MIA restaron alcance al acuerdo, afirmando que implicaba la suspensión de los bloqueos pero que seguirían movilizándose, al tiempo que se negaron a asistir al Pacto Nacional Agrario al que invitaba el Gobierno el 12 de septiembre, por considerar que no reflejaba los intereses de los campesinos sino los de los empresarios (Semana, 2013e). Entre tanto, para la misma fecha convocaron la Gran Cumbre Agraria y Popular, con el objetivo de evaluar los avances del movimiento campesino luego del paro.

El 12 de septiembre el Gobierno efectuó el Pacto Agrario con los gremios, no con los campesinos. Además, nombró a un empresario de palma de aceite, Rubén Darío Lizarralde, como ministro de agricultura. Un mes después hubo otra amenaza de paro porque el Gobierno no cumplía con sus compromisos y una ruptura en la mesa de negociaciones con Dignidad Agropecuaria (El Espectador, 2013p). El martes 3 de diciembre, cerca de 20.000 campesinos marcharon en Bogotá para protestar por el incumplimiento de los acuerdos por parte del Gobierno y pedir la renuncia del ministro Lizarralde (Semana, 2013f).

En suma, el paro agrario se mantuvo por más de 20 días, cobró una fuerza inusitada en los departamentos de Boyacá, Cundinamarca y Nariño, y ganó la solidaridad en las ciudades, sobre todo después de las polémicas declaraciones del presidente Santos. Sin embargo, al final la división entre las organizaciones convocantes y las estrategias del Gobierno rindieron frutos para acabar con la protesta. 


\section{Explicando el paro agrario}

Como se expresó líneas atrás, el enfoque de los procesos políticos trata de explicar el origen y desarrollo de la protesta mediante dos conjuntos de factores. De una parte, los elementos estructurales que pueden configurar oportunidades políticas. De otra, las estructuras de movilización y los marcos de acción colectiva que sustentan y dan sentido a la protesta.

\section{Factores estructurales}

La estructura de oportunidades políticas designa los factores del contexto político que incentivan o constriñen la acción colectiva (Tarrow, 1997, p. 49). Estas oportunidades pueden producirse tanto a nivel de la estructura política institucional como por cambios en las relaciones de poder del sistema político (McAdam, McCarthy y Zald, 1999, p. 23). Inicialmente, el concepto fue criticado por su amplitud, pues al comprender cualquier dimensión contextual corría el riesgo de perder su capacidad explicativa (Gamson y Meyer, 1999, p. 389). Por eso, autores como McAdam (1999, p. 54) se esforzaron en precisar las variables pertinentes: el grado de apertura del sistema político, la estabilidad en las coaliciones de las élites, la presencia o ausencia de aliados para el movimiento social y la capacidad de represión estatal.

Otra crítica señala que no solo las oportunidades políticas inciden en el origen y desarrollo de las movilizaciones, sino también factores sociales y culturales. En esta senda Ruch (1999, pp. 266-269) propone el concepto de estructura de contexto, para dar cuenta del contexto cultural y socioeconómico más amplio en el que tiene lugar una acción colectiva.

La crisis del sector agrario es un elemento socioeconómico necesario, aunque no suficiente, para explicar el paro agrario. Esta crisis hunde sus raíces en el cambio de modelo económico a principios de los noventa, cuando de un sector protegido por el Estado se viró hacia un esquema abierto al mercado, que llevó a una tasa negativa de crecimiento en el PIB del sector de -2.0 para 1992 y una marcada disminución de cultivos de algodón, arroz, cebada, maíz, papa, tabaco, soya, trigo y hortalizas, debido al aumento en un $700 \%$ de las importaciones, especialmente de cereales (Suhner, 2002: 25). Como consecuencia, la balanza comercial agraria entró en déficit, lo que aumentó los costos de producción agraria nacional. Esta crisis suscitó varias protestas de los campesinos, en demanda de una política agraria para contrarrestar la baja en los precios de sus productos debido a la importación y el contrabando, el aumento de costos financieros por la eliminación de los subsidios a las tasas de interés, y la reorganización las instituciones estatales del sector agropecuario (Cinep, 2013, p. 12).

Varias de estas demandas reaparecieron en el paro de 2013, debido a la agudización de la situación tras la firma de tratados de libre comercio que pusieron 
a los productores nacionales en mayor desventaja, la ausencia de una política agraria y de institucionalidad estatal para el agro y las consecuencias ambientales negativas de la política mineroenergética del Gobierno Santos (Salcedo, Pinzón y Duarte, 2013, p. 3; Cinep, 2013, p. 13). La pequeña producción campesina, algunas veces organizada en consejos comunitarios (comunidades negras), resguardos indígenas o zonas de reserva campesina, ha venido cediendo terreno, en la mayoría de ocasiones por vía de la violencia y la instrumentalización de las instituciones del Estado en función de intereses particulares, frente a la agroindustria y la gran minería (Molano, 2013).

Pero la magnitud de la protesta se explica también por un contexto político que amplió las oportunidades para la movilización y que comprende tres grandes conjuntos de factores: primero, el ciclo de protestas en el que se inscribe abre oportunidades al mostrar la vulnerabilidad del Gobierno; segundo, las negociaciones de paz amplían la agenda pública permitiendo el posicionamiento de demandas sociales no tramitadas por el sistema político y, tercero, el apoyo de diversos actores sociales y políticos contrarresta el ascenso en los niveles de criminalización y represión de la protesta.

En efecto, el paro se inscribe en un ciclo ascendente de protestas, que comprende el paro universitario de octubre de 2011, el paro nacional cafetero en febrero y marzo de 2013 (Cruz, 2012; 2013) y el paro campesino del Catatumbo, en junio y julio de ese año. Según un informe del Cinep (2014), en 2013 hubo 1027 acciones de protesta, lo que constituye el pico más elevado comparado con los registros anuales desde 1975. Así, es probable que los actores sociales opten por la movilización para realizar sus reivindicaciones al percibir que el Gobierno es vulnerable frente a este tipo de acción (Wallerstein, 2008, p. 46).

Aunque el presidente Santos llegó al Gobierno como abanderado de la causa de la seguridad democrática y se esperaba que tuviera un estilo similar al de su antecesor, Álvaro Uribe (2002-2010), lo cierto es que desde el primer momento le imprimió una dinámica distinta, que empezó por la recomposición de las relaciones diplomáticas con los países vecinos y la apertura de negociaciones de paz con las Farc en agosto de 2012 (Cruz, 2014). Por consiguiente, hubo una apertura de la agenda pública para que actores sociales diversos posicionaran sus reivindicaciones, que se acompañó con el reconocimiento del derecho a la protesta y la oposición política, lejos de la condena que de ella se hizo en el anterior Gobierno (López, 2014). Pero también hubo una división entre las élites políticas representadas por Santos y Uribe, lo que se traduciría en oportunidades políticas para los movimientos sociales.

Con todo, durante el paro agrario el Gobierno puso en marcha estrategias de criminalización y represión. Se trató de desviar la atención de las demandas de la protesta hacia su carácter "vandálico" y la supuesta infiltración de la guerrilla. El 29 de agosto, a raíz de los enfrentamientos en varias ciudades entre policía y manifestantes, el ministro de Defensa, Juan Carlos Pinzón, llamó a estos últimos "vándalos", un calificativo que pronto ganó resonancia entre los funcionarios y 
en la prensa (El Espectador, 2013q). Posteriormente, el mismo ministro afirmaría que sus acciones eran producto de la infiltración de las Farc (León, 2013). De igual manera, el director de la Policía, general Rodolfo Palomino, declaró: "hay una penetración, infiltración y manipulación desmedida de las Farc en estos paros" (Semana, 2013g).

La criminalización de la protesta se hizo efectiva con base en la Ley 1453 o "ley de seguridad ciudadana", puesto que en su artículo 353 literal a, penaliza la obstrucción de vías públicas, que es el principal repertorio de acción de los campesinos en protesta. De hecho, antes de iniciar el paro, el 16 de agosto, el mismo presidente Santos dio la orden de no permitir bloqueos: "me vigilan estos paros y por ningún motivo me permitan que me bloqueen vías" (El Tiempo, 2013k). El ministro del Interior, Fernando Carrillo, instó a los mandatarios locales a seguir esta directriz aplicando la legislación mencionada (El Tiempo, 20131).

La represión de la protesta presentó un incremento considerable si se compara, por ejemplo, el paro universitario (2011) con el paro agrario (2013) (Cruz, 2015). Según el investigador del Cinep, William Rozo (2013, p. 39), durante el paro hubo 873 capturas y el $57 \%$ de ellas condujo a judicialización. Según el programa Somos Defensores (2014, p. 5), durante el paro ,902 personas fueron víctimas de algún tipo de agresión. Del total de los casos, 15 personas fueron asesinadas; 7 , víctimas de algún tipo de acto cruel o tortura, entre ellos un abuso sexual; 315 ,detenidas arbitrariamente; 40, víctimas de fuertes golpizas; 329, a causa de los ataques resultaron con algún tipo de lesión o herida, y 5, con heridas graves que les derivó incapacidad parcial o total. Es de resaltar que en 70 \% de los casos, la agresiones estuvieron acompañadas por otros tipos de violaciones.

Para el primer día de paro, el Gobierno dispuso de 16.000 policías para controlar las manifestaciones, pero pronto las principales vías e incluso las principales ciudades fueron militarizadas (El Tiempo, 2013m). Se denunciaron hechos de represión, aún sin bloquear vías, como panfletos amenazantes contra líderes de organizaciones campesinas o participantes del paro, infiltraciones de personas sospechosas o miembros de la fuerza pública en las asambleas y reuniones de los campesinos, empadronamientos y tomas de fotografías a los manifestantes que se movilizaban por distintos lugares del territorio nacional, detenciones ilegales de personas que participaban en la movilización, impedimentos por parte de la fuerza pública a la circulación de vehículos con personas que participaban de la protesta, entre otras. El 23 de agosto, a cuatro días de paro, se informaba de 175 personas detenidas en todo el país (El Tiempo, 2013n).

A pesar de eso, el presidente Santos respaldó la represión cuando afirmó que la fuerza pública estaba cumpliendo con su deber y que la violencia se debía a las infiltraciones (El Espectador, 2013r). Uno de los voceros de la MIA, Hubert Ballesteros, fue capturado, acusado de tener nexos con las Farc, lo que fue rechazado por las organizaciones sociales como un "montaje judicial" (El Espectador, 2013s). Tras una semana de protestas, en las redes sociales virtuales empezaron a hacerse virales, videos en los que aparecían agentes de policía abusando de 
su fuerza en contra de manifestantes indefensos, personas de la tercera edad, niños y mujeres embarazadas; haciendo un uso inadecuado de las armas de "letalidad reducida" -al disparar a quemarropa los gases lacrimógenos, hacerlo en lugares cerrados o usar indiscriminadamente las pistolas eléctricas-, ingresando a las viviendas de los campesinos sin orden judicial para generar destrozos o hurtando las provisiones de los campesinos en protesta (Canal Capital, 2013; Semana, 2013h; MOVICE-CCEEU, 2013, p. 28).

Los materiales visuales generaron tal impacto en la opinión pública que el mismo presidente Santos, en un hecho inédito, tuvo que pedir disculpas por los excesos de la Policía (El Espectador, 2013t). El nivel de represión llevó a los congresistas boyacenses Jorge Londoño y Carlos Andrés Amaya, quien había sido agredido, a promover un debate de control político al ministro de Defensa y al director de la Policía (La Silla Vacía, 2013b).

Sin embargo, ni la criminalización ni la represión disminuyeron. El 30 de agosto el general Palomino difundió un afiche, el "cartel de los vándalos", que incluía fotografías de 48 jóvenes, muchos de ellos menores de edad, por los que ofreció recompensas hasta de cien millones de pesos, presuntamente por participar en las protestas del día anterior en Bogotá (Semana, 2013i). El hecho fue criticado como una violación al derecho del debido proceso y a los derechos de los menores. En fin, las protestas del 29 de agosto fueron un parteaguas en la implementación de la represión, puesto que el presidente Santos ordenó la militarización de varias ciudades, principalmente de Bogotá, en contravía del manejo alternativo de la protesta ensayado en días anteriores por el alcalde Gustavo Petro (Semana, 2013c).

Pese a los altos niveles de represión y criminalización, la protesta pudo mantenerse gracias al apoyo que recibió de diversos actores, pero, sobre todo, de los pobladores de las ciudades. En este fenómeno incidió la equivocación del presidente Santos, al tratar de reducir la magnitud de la protesta declarando que no existía. Pero sobre todo fue producto de la importancia que han tomado las nuevas tecnologías de información y comunicación en el mundo rural colombiano, puesto que las convocatorias a los cacerolazos en las ciudades y la difusión de los abusos policiales se hicieron por redes sociales virtuales. No obstante, también hubo diversas manifestaciones de apoyo de actores sociales y políticos organizados. Con base en un seguimiento de los portales virtuales de Semana, El Espectador, Rebelión, Prensa Rural, El Tiempo y La Silla Vacía, la tabla 1 muestra distintas formas de apoyo que recibió el paro.

En fin, existen una serie de factores estructurales y coyunturales que configuraron oportunidades políticas para el paro agrario, más allá de considerarlo una reacción frente a la crisis del sector. La vulnerabilidad del Gobierno Santos frente a las protestas, la ampliación de la agenda pública en el contexto del proceso de paz y el apoyo de diversos actores contribuyeron a originar y mantener la protesta pese a los altos niveles de criminalización y represión. No obstante, 
dichas oportunidades no habrían podido aprovecharse sin el concurso de factores subjetivos: las organizaciones campesinas y sus marcos de acción colectiva.

Tabla 1. Apoyos al paro nacional agrario 2013

\begin{tabular}{|c|c|}
\hline Fecha & Manifestación de apoyo \\
\hline 4 de agosto & $\begin{array}{l}\text { Durante la clausura de sus sesiones, el Foro de Porto Alegre manifiesta su } \\
\text { apoyo al paro. }\end{array}$ \\
\hline 16 de agosto & $\begin{array}{l}\text { La Unión Sindical Obrera emite un comunicado de solidaridad con el paro. } \\
\text { paro en Cali. }\end{array}$ \\
\hline 20 de agosto & $\begin{array}{l}\text { En Manizales, estudiantes, profesores, sindicatos, comerciantes, transpor- } \\
\text { tadores, camioneros y carretilleros manifiestan su apoyo al paro. }\end{array}$ \\
\hline 20 de agosto & Surgen marchas de apoyo al paro en Cali. \\
\hline 20 de agosto & El expresidente Uribe y sectores afines manifiestan su apoyo al paro. \\
\hline 21 de agosto & $\begin{array}{l}\text { El capítulo venezolano de Marcha Patriótica realiza un plantón frente al } \\
\text { consulado de Colombia, en Caracas, como muestra de apoyo al paro. }\end{array}$ \\
\hline 23 de agosto & $\begin{array}{l}\text { El Gobierno distrital en Bogotá ordena a la Policía no usar la fuerza en } \\
\text { contra de los manifestantes. }\end{array}$ \\
\hline 24 de agosto & $\begin{array}{l}\text { La bancada de congresistas de Boyacá denuncia en el Congreso las agre- } \\
\text { siones del Esmad en contra de la ciudadanía y piden intervención inmediata } \\
\text { del presidente Santos. }\end{array}$ \\
\hline 24 de agosto & $\begin{array}{l}\text { Empleados de Corabastos en Bogotá marchan para expresar su solidaridad } \\
\text { con el paro. }\end{array}$ \\
\hline 26 de agosto & $\begin{array}{l}\text { Presos políticos de la cárcel de Palo Gordo (Santander) publican un comu- } \\
\text { nicado de solidaridad con el paro nacional agrario. }\end{array}$ \\
\hline 26 de agosto & $\begin{array}{l}\text { La Unión Sindical Obrera anuncia un paro de } 24 \text { horas en apoyo al paro } \\
\text { nacional agrario. }\end{array}$ \\
\hline 26 de agosto & $\begin{array}{l}\text { Diputados de la Asamblea de Boyacá anuncian demanda por abusos del } \\
\text { Esmad ante la Organización de Naciones Unidas (ONU). }\end{array}$ \\
\hline 27 de agosto & $\begin{array}{l}\text { El alcalde de Bogotá, Gustavo Petro, manifiesta su apoyo al paro: convoca } \\
\text { a los campesinos a un "pacto social por la tierra" y acompaña, con provisio- } \\
\text { nes y otros elementos, a los manifestantes en Usme. }\end{array}$ \\
\hline 28 de agosto & $\begin{array}{l}\text { Congresistas de Boyacá citan a un debate de control político al Gobierno } \\
\text { nacional y a la Policía debido a los abusos de autoridad durante el paro. }\end{array}$ \\
\hline 29 de agosto & $\begin{array}{l}\text { Surgen manifestaciones de apoyo al paro en Francia, Alemania, México, } \\
\text { Londres, Buenos Aires, San José de Costa Rica, Montevideo, Frankfurt, } \\
\text { Santiago de Chile, Bélgica y Holanda. }\end{array}$ \\
\hline
\end{tabular}




\section{Factores subjetivos}

Toda acción colectiva requiere de unas redes de relaciones sociales que la soporten y de la creación de sentidos que hagan posible el compromiso individual con una causa común. Dichas redes de relaciones están comprendidas en el concepto de estructuras de movilización, "canales colectivos tanto formales como informales, a través de los cuales la gente puede movilizarse e implicarse en la acción colectiva" (McAdam, Mc-Carthy y Zald, 1999, p. 25). Así, estas estructuras pueden ser organizaciones del movimiento social, con diversos grados de formalización, e incluso profesionalización, dedicadas a promover la acción colectiva, o, bien, otras formas de asociación con fines diversos (familia, redes de amigos, de trabajo, etc.), que, aunque no tienen como finalidad promover la movilización, pueden vincularse a ella en determinadas circunstancias (McCarthy, 1999, p. 206).

El paro agrario fue convocado por tres grandes plataformas nacionales, que a su vez comprenden distintas formas de organización presentes en el campo colombiano: la Mesa Nacional Agraria y Popular de Interlocución y Acuerdo (MIA), el Coordinador Nacional Agrario (CNA) y Dignidad Agropecuaria.

La MIA es una iniciativa de Marcha Patriótica, plataforma de diversos movimientos sociales rurales y urbanos que nació en 2013 y en la que participan, entre otras, la Federación Nacional Sindical Agropecuaria (Fensuagro) y la Asociación Nacional de Zonas de Reserva Campesina (Anzorc). La figura de la mesa de interlocución nació en el marco del proceso de construcción de la zona de reserva campesina del Catatumbo, que se propone como una alternativa de ordenamiento territorial para resolver diversos problemas de esta región, encabezado por la Asociación Campesina del Catatumbo (Ascamcat). Allí se formó una MIA desde 2009, con el fin de entablar negociaciones con el Gobierno. La figura operó durante las protestas de junio y julio de 2013, de ahí que fuese retomada en el paro agrario de agosto y septiembre, tanto a nivel nacional como en mesas regionales. La organización se autodefine de la siguiente forma:

La MIA es una organización que aglutina a pequeños propietarios colonos, a campesinos con acceso a la tierra pero sin propiedad formalizada, a productores de cultivos declarados de uso ilícito y a trabajadores rurales sin tierra. Asimismo reúne a comunidades mineras artesanales del sur de Bolívar, nordeste de Antioquia, Córdoba y Chocó. En cuanto a la geografía que abarca este conjunto de campesinos, colonos y mineros, sus organizaciones están presentes en los departamentos de Meta, Caquetä, Putumayo, Huila, Córdoba, Cauca, Valle del Cauca, Boyacá, Santander, Norte de Santander, Tolima, Bolívar, Chocó, Sucre, Meta, Arauca y Antioquia. (MIA, 2015, p. 16)

El origen del CNA se remonta hacia el I Foro Nacional Agrario, que se realizó en Bogotá en 1997, donde convergieron varios procesos organizativos de 
distintas regiones, como el Comité de Integración Social del Catatumbo (CISCA), la Asociación Campesina de Antioquia (ACA), El Comité de Integración del Macizo Colombiano (CIMA), el Comité de Integración del Galeras (CIGA) y la Federación Agraria y Minera del sur de Bolívar (Fedeagrobismol). El CNA fue fundamental para la creación del Congreso de los Pueblos, una plataforma de movimientos sociales análoga a la Marcha Patriótica, en 2010, cuyos antecedentes se hallan en la Minga de Resistencia Social de 2008 (Salcedo, Pinzón y Duarte, 2013, p. 8). En consecuencia, su base originalmente de pequeños campesinos, se ha diversificado, ampliándose hacia indígenas, afrodescendientes, pequeños mineros e incluso algunos sectores urbanos. En fin, el CNA hace presencia en regiones como Cauca, Chocó, Nariño, Antioquia, Arauca, Norte de Santander, Bolívar, Tolima, Valle, Huila, Boyacá, Casanare, Cundinamarca y Putumayo (Cinep, 2012, p. 9).

Dignidad Agropecuaria reúne varias plataformas organizativas regionales inspiradas en Dignidad Cafetera, organización con arraigo en el Eje Cafetero que lideró el paro de febrero y marzo de 2013. Según César Pachón (Duzán, 2014, pp. 48-49), uno de sus líderes, los cultivadores de papa de Boyacá realizaron dos paros, el 16 de noviembre de 2011 y el 7 de mayo de 2013. Ese día Pachón participó en una audiencia en el Congreso, en la que recibió el apoyo de los caficultores. Dado que en ese momento representaba la "dignidad papera" y la "dignidad cebollera", les propuso formar la Dignidad Agropecuaria: "El primero de junio empezamos a hacer las reuniones de dignidad agropecuaria porque veíamos que no había resultados ni del paro cafetero ni de nuestras actas y además llevábamos dos meses seguidos con nuestros propios recursos yendo a unas mesas con el Gobierno que no solucionaban nada porque además ponían funcionarios de mando bajo" (Duzán, 2014, p. 48). En julio de 2013, quienes formaron Dignidad Agropecuaria, campesinos de Cundinamarca, Boyacá, Nariño, Santander y Norte de Santander, cultivadores de papa, cebolla, arroz y productores de leche, decidieron no continuar en las mesas de negociación con el Gobierno. Los cafeteros pusieron como fecha para iniciar el paro el 19 de agosto.

Si bien el impulso de la movilización corrió por cuenta de estas tres grandes estructuras organizativas, tanto en las áreas urbanas como en las rurales implicó otro tipo de redes de relaciones y formas asociativas formales e informales. Esto explica por qué en departamentos como Boyacá y Nariño, que muchas veces son concebidos "conservadores", hubo una amplia participación del campesinado en las protestas.

En rigor, en estas regiones no se movilizaron organizaciones de movimientos sociales propiamente dichas, sino comunidades, en el sentido en que Zibechi (2006) le confiere a este concepto, es decir, las relaciones sociales familiares, de vecindad, de compadrazgo, que sustentan la vida cotidiana vincularon a las personas a la acción colectiva. Las comunidades tenían incentivos para movilizarse por el hecho de que poblaciones enteras, no solo los pequeños y medianos productores agropecuarios sino también los comerciantes, los transportadores 
y los proveedores de otros servicios, dependen de la economía agropecuaria, lo cual hizo que se vincularan a las demandas de los productores.

Pero no solo las relaciones cara a cara contribuyeron a la movilización. Como anteriormente se mencionó, el uso de las redes sociales virtuales desempeñó un papel fundamental para que la protesta se extendiera con los cacerolazos hacia las ciudades. Sin embargo, esto no habría sido posible si no hubiese existido una interpelación a la identidad campesina que tuvo un eco entre los pobladores urbanos en clave de defensa de su dignidad.

Este factor está comprendido en los marcos de acción colectiva, esquemas interpretativos de la realidad que construyen los participantes en un movimiento social (Snow y Benford, 1992, p. 137). Para Tarrow (1997, p. 57), son "significados compartidos que impulsan a las personas a la acción colectiva". El proceso de creación de estos esquemas presta atención al papel activo de los actores pues "tanto la cultura como el proceso enmarcador de ideas se conciben estratégicamente" (Zald, 1999, p. 369; Rivas, 1998, pp. 206-207). Su objetivo es "forjar formas compartidas de considerar el mundo y a sí mismos que legitimen y muevan a la acción colectiva" (McAdam, McCarthy y Zald, 1999, p. 27). Por esa razón, los procesos de enmarcado implican un conflicto entre distintas visiones del mundo, formas de explicar los problemas, soluciones y cursos de acción. Esta disputa tiene lugar tanto en el interior de los movimientos como en su ámbito externo, pues los marcos son cuestionados por adversarios y funcionarios estatales (Zald, 1999, p. 370; Rivas, 1998, p. 207).

En el paro agrario de 2013 no hubo en estricto sentido un marco de acción colectiva unificado, puesto que no se consiguió acordar un solo pliego de demandas. No obstante, los tres documentos permiten aproximarse al sentido que enmarcó la protesta social, el tipo de problemas sociales que la suscitaron y sus responsables. En todos los casos hay una identidad compartida como "campesinos" y el principal adversario de sus propuestas es el Gobierno, que sistemáticamente incumple los acuerdos con las comunidades, no reconoce al campesino como un actor político legítimo y ha adoptado políticas agrarias contrarias a los intereses de los pequeños y medianos productores pero favorables a las grandes empresas de agronegocios.

Sin embargo, entre los tres documentos hay diferencias notables en relación con los problemas que pretenden resolver. El pliego de Dignidad Agropecuaria hace énfasis en el cumplimiento de acuerdos de protestas anteriores, la reducción de los precios de los insumos y la protección de la producción nacional frente a las importaciones propiciadas por los tratados de libre comercio, el contrabando y la extensión del subsidio cafetero (Protección del Ingreso Cafetero) (Nasaacin, 2013). El pliego de la MIA plantea una agenda de problemas más amplia (aunque comprende los anteriores), puesto que reclama soluciones (políticas agrarias estructurales, el acceso a la propiedad de la tierra), la reivindicación de ciertas figuras (como las zonas de reserva campesina), e incluso garantizar los derechos políticos de los campesinos y otros actores sociales y políticos (MIA, 2013). 
Finalmente, el pliego del CNA comparte varias de las reivindicaciones con el de la MIA, aunque hace un énfasis en las demandas de los pueblos indígenas y afros, como el reconocimiento de autonomía y territorio para la construcción de vida digna (Congreso de los Pueblos, 2013).

En buena medida, las diferencias en los diagnósticos y las propuestas para resolver los problemas se derivan de situaciones distintas que enfrentan los campesinos aglutinados en torno a cada uno de los pliegos. Así, Dignidad Agropecuaria representa intereses de medianos productores agrícolas. Por esa razón, su pliego de peticiones se enfoca en regulaciones de precios, importaciones e insumos. Sus preocupaciones no están enfocadas en los problemas de la tierra y el territorio, propios de campesinos pobres, víctimas del despojo violento, a menudo dedicados al cultivo de coca y asentados en zonas de reciente colonización. Por eso, en contraste con el pliego del CNA o el de la MIA, no reivindica una reforma agraria, alternativas económicas para la sustitución de cultivos ilícitos, ni el reconocimiento formal de las zonas de reserva campesina. Los campesinos representados por el CNA y la MIA provienen de zonas de reciente colonización, cuyas urgencias están enfocadas en garantizar la propiedad de la tierra, por eso abanderan las zonas de reserva campesina, infraestructura y servicios públicos (Dorado, 2013).

\section{Corolario}

El paro agrario de 2013 tuvo lugar en un contexto caracterizado por la profundización de la crisis del sector, pero al mismo tiempo por oportunidades políticas provistas principalmente por la relativa apertura política resultado de los diálogos de paz entre el Gobierno Nacional y las Farc. Sin embargo, un elemento fundamental para que dichas oportunidades fuesen aprovechadas fue la construcción, en un período reciente, de estructuras de movilización. Así, la Marcha Patriótica, el Congreso de los Pueblos, la MIA, el CNA o Dignidad Agropecuaria, han significado la posibilidad de disputar en la esfera pública la significación de los problemas campesinos a partir de la producción de sus propios esquemas interpretativos de la realidad, que han vinculado a diversos actores.

A pesar de las divisiones que caracterizaron la protesta, entre organizaciones que representan núcleos campesinos con diferentes formas de vida y problemáticas disímiles, el paro ubicó en la agenda pública y, en especial, en la discusión sobre la construcción de paz en Colombia, la crisis por la que atraviesan distintos sectores del campesinado, los pequeños y medianos productores, pero también los campesinos sin tierra o despojados violentamente de ella, que pugnan por soluciones gubernamentales.

Los altos niveles de represión y criminalización de la protesta campesina, que llegaron a tal extremo que el mismo presidente Santos se vio obligado a pedir disculpas por los excesos de la fuerza pública, fueron contrarrestados por el 
apoyo de diversos actores sociales y políticos organizados, pero sobre todo por la solidaridad de los habitantes de las ciudades que no han roto sus vínculos, simbólicos, socioculturales y políticos, con el campo, pese al descuido que sus problemáticas han merecido por parte del Estado.

Paradójicamente, el paro también mostró una cara desconocida del campo colombiano y sus complejas transformaciones en el mundo contemporáneo. Lejos de constituir un sector en decadencia, la manifestación puso de presente la vitalidad del tejido social que anida en las distintas regiones del país, pero también su adaptación a los desafíos que dicho mundo le plantea, cuya más importante evidencia se encuentra en el manejo de las redes sociales virtuales y de herramientas tecnológicas como los teléfonos móviles y las cámaras digitales para denunciar la represión de la protesta.

\section{Referencias}

Bermúdez, A. (2013). El Gobierno se concentra en un eslabón del paro, mientras se le crecen los otros, recuperado de http://lasillavacia.com/historia/el-gobiernose-concentra-en-un-eslabon-del-paro-mientras-se-le-crecen-los-otros-45406

Canal Capital. (2013). Especial "Por el respeto", recuperado el 29 de marzo de 2015 de https://www.youtube.com/watch?v=tTwJoYcROoM

Centro de Investigación y Educación Popular. (2013). Luchas sociales, derechos humanos y representación política del campesinado 1988-2012. Bogotá: Centro de Investigación y Educación Popular.

Centro de Investigación y Educación Popular. (2014). Informe especial. Luchas sociales en Colombia 2013. Bogotá: Centro de Investigación y Educación Popular.

Congreso de los Pueblos. (2013). Pliego agrario y mineroenergético hacia un país con paz y vida digna, recuperado de http://congresodelospueblos.org/item/543-pliegoagrario-y-minero-energetico-hacia-un-pais-con-paz-y-vida-digna.html

Cruz, E. (2012). La MANE y el paro nacional universitario de 2011 en Colombia. Ciencia Política, (14), 140-193.

Cruz, E. (2013). Todos somos hijos del café. Sociología política del paro nacional cafetero. Entramado, 9(2), 138-158.

Cruz, E. (2014). Dignidad en movimiento. El ascenso de la movilización social en Colombia. Confluenze. Revista di Studi Iberoamericani Universitá di Bologna, 6(25), 241-275.

Cruz, E. (2015). El derecho a la protesta social en Colombia. Pensamiento Jurídico, $42,47-69$. 
Dorado, F. (2013). Las complejidades del Paro Nacional Agrario. Rebelión, recuperado de http://www.rebelion.org/noticia. php?id=172647\&titular=las-complejidades-del-paro-nacional-agrario-

Duzán, M. (2014). Emputados. El libro de los indignados colombianos. Bogotá: Planeta.

El Espectador. (19 de agosto de 2013a,). Habrá diálogo, pero sin bloqueos. El Espectador, recuperado de http://www.elespectador.com/noticias/nacional/ habra-dialogo-sin-bloqueos-articulo-440988

E1 Espectador. (21 de agosto de 2013c,). Cinco manifestantes y 10 uniformados, heridos en Ubaté. El Espectado, recuperado de http://www.elespectador.com/noticias/nacional/ cinco-manifestantes-y-10-uniformados-heridos-ubate-video-441274

El Espectador. (21 de agosto de 2013d). El paro ya hace sentir sus consecuencias. El Espectador, recuperado de http://www.elespectador.com/noticias/ economia/el-paro-ya-hace-sentir-sus-consecuencias-articulo-441666

El Espectador. (21 de agosto de 2013e). En medio de paro agrario y cafetero, piden renuncia de Minagricultura. El Espectador, recuperado de http://www.elespectador.com/noticias/politica/ medio-de-paro-agrario-y-cafetero-piden-renuncia-de-mina-articulo-441334

E1 Espectador. (23 de agosto de 2013f). Arroceros preocupados por efectos negativos del paro agrario. El Espectador, recuperado de http://www.elespectador.com/noticias/economia/ arroceros-preocupados-efectos-negativos-del-paro-agrari-articulo-442178

El Espectador. (24 de agosto de 2013g). CICR denuncia 28 agresiones a misión médica en paro agrario. El Espectador, recuperado de http://www.elespectador.com/noticias/salud/ cicr-denuncia-28-agresiones-mision-medica-paro-agrario-articulo-442271

El Espectador. (25 de agosto de 2013h). “El paro está bajo control y los problemas se están solucionando": Santos. El Espectador, recuperado de http://www.elespectador.com/noticias/politica/ el-paro-esta-bajo-control-y-los-problemas-se-estan-solu-articulo-442317

El Espectador. (22 de agosto de 2013i). Video revela excesos de la policía en paro agrario. El Espectador, recuperado de http://www.elespectador.com/noticias/ nacional/video-revela-excesos-de-policia-paro-agrario-articulo-441790

E1 Espectador. (26 de agosto de 2013j). Minagricultura dice que está dispuesto a renunciar si con eso se arregla el paro. El Espectador, recuperado de http://www.elespectador.com/noticias/nacional/ minagricultira-dice-esta-dispuesto-renunciar-si-eso-se-articulo-442658 
El Espectador. (28 de agosto de 2013k). Por bloqueos en Bogotá, piden no sacar basura, recuperado de http://www.elespectador.com/noticias/bogota/ bloqueos-bogota-piden-no-sacar-basura-articulo-443119

El Espectador. (3 de septiembre de 20131). Tras 16 días del paro agrario, persisten bloqueos en siete departamentos. El Espectador, recuperado de http://www.elespectador.com/noticias/nacional/ tras-16-dias-del-paro-agrario-persisten-bloqueos-siete-articulo-444168

E1 Espectador. (3 de septiembre de 2013m). Gobierno logra acuerdo para levantar paro en Arauca. El Espectador, recuperado de http://www.elespectador.com/noticias/nacional/ gobierno-logra-acuerdo-levantar-paro-arauca-articulo- 444228

El Espectador. (5 de septiembre de 2013n). Gobierno acordó congelar decreto 970. El Espectador, recuperado de http://www.elespectador.com/noticias/ nacional/gobierno-acordo-congelar-decreto-970-articulo-444540

El Espectador. (6 de septiembre de 2013o). Se levanta paro en el Huila. El Espectador, recuperado de http://www.elespectador.com/noticias/nacional/ se-levanta-paro-el-huila-articulo-444925

El Espectador. (18 de octubre de 2013p). Estalla nuevo conato de paro agrario al romperse diálogos de Gobierno y campesinos. El Espectador, recuperado de http://www.elespectador.com/noticias/politica/ estalla-nuevo-conato-de-paro-agrario-al-romperse-dialog-articulo-453039

El Espectador. (19 de agosto de 2013q). Presencia militar se va a incrementar en algunas ciudades: Mindefensa. El Espectador, recuperado de http://www.elespectador.com/noticias/nacional/ presencia-militar-se-va-incrementar-algunas-ciudades-mi-articulo-443318

El Espectador. (23 de agosto de 2013r). Fuerza Pública cumple con su deber durante los paros: Santos. El Espectador, recuperado de http://www.elespectador.com/noticias/nacional/ fuerza-publica-cumple-su-deber-durante-los-paros-santos-articulo-442134

El Espectador. (25 de agosto de 2013s). Gobierno y campesinos siguen en diálogo. El Espectador, recuperado de http://www.elespectador.com/noticias/ nacional/gobierno-y-campesinos-siguen-dialogo-articulo-442435

El Espectador. (26 de agosto de 2013t). Santos: si hubo abusos de la policía, ofrezco disculpas. El Espectado, recuperado de http://www.elespectador.com/noticias/nacional/ santos-si-hubo-abusos-de-policia-ofrezco-disculpas-articulo-442634

El Tiempo. (16 de agosto de 2013a). Gobierno pide a organizaciones sociales no bloquear vías en el paro. El Tiempo, recuperado de http://www.eltiempo. com/archivo/documento/CMS-12995825 
El Tiempo. (23 de agosto de 2013b,). Paro del agro ha dejado un muerto y 175 detenidos. El Tiempo, recuperado de http://www.eltiempo.com/archivo/ documento/CMS-13009673

El Tiempo. (19 de agosto de 2013c). Bloqueos y movilizaciones en primer día de paro. El Tiempo, recuperado de http://www.eltiempo.com/archivo/ documento/CMS-13003724

El Tiempo. (21 de agosto de 2013d). Disturbios por el paro llegaron hasta el casco urbano de Tunja. El Tiempo, recuperado de http://www.eltiempo. com/archivo/documento/CMS-13006923

El Tiempo. (22 de agosto de 2013e). Disturbios en Zipaquirá por el paro nacional. El Tiempo, recuperado de http://www.eltiempo.com/archivo/documento/ CMS-13007402

El Tiempo. (23 de agosto de 2013f). Gobierno escuchará a líderes campesinos si acaban con los bloqueos. El Tiempo. Recuperado de http://www.eltiempo. com/archivo/documento/CMS-13012124

El Tiempo. (26 de agosto de 2013g). Unas 50.000 personas participaron en cacerolazo en Tunja. El Tiempo, recuperado de http://www.eltiempo.com/ archivo/documento/CMS-13013346

El Tiempo. (27 de agosto de 2013h). Alimentos se han encarecido más del $100 \%$ por paro. El Tiempo, recuperado de http://www.eltiempo.com/archivo/ documento/CMS-13015066

El Tiempo. (30 de agosto de 2013i). Jornada de disturbios dejó cuatro muertos en el país. El Tiempo, recuperado de http://www.eltiempo.com/archivo/ documento/CMS-13034984

El Tiempo. (30 de agosto de 2013j). Intenciones de promotores de paro quedaron en evidencia: Vargas Lleras. El Tiempo, recuperado de http://www.eltiempo. com/archivo/documento/CMS-13035579

El Tiempo. (16 de agosto de 2013k). Esperan que marcha de agricultores y ganaderos no altere orden público. El Tiempo, recuperado de http://www. eltiempo.com/archivo/documento/CMS-12998014

El Tiempo. (16 de agosto de 20131). Gobierno pide a organizaciones sociales no bloquear vías en el paro. El Tiempo, recuperado de http://www.eltiempo. com/archivo/documento/CMS-12995825

El Tiempo. (17 de agosto de 2013m). Gobierno dispone de 16.000 policías para frenar bloqueos el lunes. El Tiempo, recuperado de http://www.eltiempo. com/archivo/documento/CMS-12999443 
El Tiempo. (23 de agosto de 2013n). Paro del agro ha dejado un muerto y 175 detenidos. El Tiempo, recuperado de http://www.eltiempo.com/archivo/ documento/CMS-13009673

Gamson, W. y Meyer, D. (1999). Marcos interpretativos de la oportunidad política. En D. McAdam, J. McCarthy y M. Zald (eds.), Movimientos sociales: perspectivas comparadas. Oportunidades políticas, estructuras de movilización y marcos interpretativos culturales (pp. 389-412). Madrid: Itsmo.

La Silla Vacía. (22 de agosto de 2013a). Los cafeteros del Huila ahora sí se suman al paro. La Silla Vacía, recuperado de http://lasillavacia.com/queridodiario/ los-cafeteros-del-huila-ahora-si-se-suman-al-paro-45455

La Silla Vacía. (26 de agosto de 2013b). Al negar el paro, Santos le echa más gasolina al fuego. La Silla Vacía, recuperado de http://lasillavacia.com/historia/ al-negar-el-paro-santos-le-echa-mas-gasolina-al-fuego-45476

León, J. (2013). El paro, el fracaso del equipo político de Santos. La Silla Vacía, recuperado de http://lasillavacia.com/historia/ el-paro-el-fracaso-del-equipo-politico-de-santos-45512

López, F. (2014). Las ficciones del poder. Bogotá: Universidad Nacional, Debate.

McAdam, D., McCarthy, J. y Zald, M. (1999). Movimientos sociales: perspectivas comparadas. Oportunidades políticas, estructuras de movilización y marcos interpretativos culturales. Madrid: Itsmo.

McAdam, D., Tarrow, S. y T. Ch. (2005). Dinámica de la contienda política. Barcelona: Hacer.

McCarthy, D. (1999). Adoptar, adaptar e inventar límites y oportunidades. En D. McAdam, J. McCarthy y M. Zald (eds.), Movimientos sociales: perspectivas comparadas. Oportunidades políticas, estructuras de movilización y marcos interpretativos culturales (pp. 205-220). Madrid: Itsmo.

Melucci, A. (1999). Acción colectiva, vida cotidiana y democracia. México, D. F.: El Colegio de México.

Mesa Nacional Agropecuaria y Popular de Interlocución y Acuerdo (MIA). (2015). Del paro nacional agrario a la cumbre agraria, campesina, étnica y popular. Bogotá: MIA.

Mesa Nacional Agropecuaria y Popular de Interlocución y Acuerdo (MIA). (2013). Pliego de peticiones del paro nacional agrario y popular. Recuperado de http://prensarural.org/spip/spip.php?article11620

Molano Bravo, A. (2013). Dignidad campesina. Entre la realidad y la esperanza. Bogotá: Icono. 
Movimiento Nacional de Víctimas de Crímenes de Estado. Coordinación Colombia Europa Estados Unidos. (2013). Informe sobre protesta social y derechos humanos. Recuperado el 29 de marzo de 2015 de http://www. ddhhcolombia.org.co/sites/default/files/files/pdf/CCEEU\%20y\%20Movice_ Informe $\% 20$ ante $\% 20 \mathrm{CIDH} \% 20$ sobre $\% 20$ Criminalizacin $\% 20 \mathrm{de} \% 201 \mathrm{a} \% 20$ Protesta\%20Social\%20en\%20Colombia.pdf

Nasaacin. (1. ํ de agosto de 2013). El 19 de agosto todos a la movilización nacional cafetera y agropecuaria, recuperado de http://www.nasaacin.org/index. php/informativo-nasaacin/3-newsflash/5992-el-19-de-agosto-todos-a-lamovilizacion-nacional-cafetera-y-agropecuaria

Olson, M. (1992). La lógica de la acción colectiva. En A. Batlle (ed.), Diez textos básicos de ciencia política (pp. 203-220). Barcelona: Ariel.

Prensa Rural. (25 de julio de 2013a,). Paro agrario en Colombia comenzaría el 19 de agosto. Prensa Rural. Recuperado de 2013 http://prensarural.org/spip/ spip.php?article11466

Prensa Rural. (19 de agosto de 2013b). Continúa el Paro Nacional Agrario, en rechazo a las políticas neoliberales. Prensa Rural, recuperado de http:// prensarural.org/spip/spip.php?article11742

Prensa Rural. (29 de agosto, 2013c). El paro agrario de Marcha Patriótica. Prensa Rural, recuperado de http://prensarural.org/spip/spip.php?article11895

Programa Somos Defensores. (2014). D de Defensa. Informe anual 2013 del Sistema de Información sobre Agresiones contra Defensores y Defensoras de Derechos Humanos en Colombia, recuperado de http://somosdefensores.org/attachments/article/117/SIADDHH\%202013.pdf

Rivas, A. (1998). El análisis de los marcos: una metodología para el estudio de los movimientos sociales. En P. Ibarra y B. Tejerina (eds.), Los movimientos sociales. Transformaciones políticas y cambio cultural (pp. 181-215). Madrid: Trotta.

Rozo, W. (2013). Esmad, arma letal. Cien Días, (80), 39-43.

Ruch, D. (1999). El impacto de los contextos nacionales sobre la estructura de los movimientos sociales: un estudio comparado transnacional y entre movimientos. En D. McAdam, J. McCarthy y M. Zald (eds.), Movimientos sociales: perspectivas comparadas. Oportunidades politicas, estructuras de movilización y marcos interpretativos culturales (pp. 262-287). Madrid: Itsmo..

Salcedo, L., Pinzón, R. y Duarte, C. (2013). El paro nacional agrario: un análisis de los actores agrarios y los procesos organizativos del campesinado colombiano (inédito).

Semana. (23 de agosto de 2013a). Paro campesino deja ya tres muertos tras cinco días. Semana recuperado de http://www.semana.com/nacion/articulo/ paro-campesino-deja-tres-muertos-tras-cinco-dias/355049-3 
Semana. (29 de agosto de 2013b). Protestas, furia, vandalismo y tres muertos. Semana, recuperado de http://www.semana.com/nacion/articulo/ protestas-furia-vandalismo-tres-muertos/355735-3

Semana. (30 de agosto de 2013c). Santos ordena la militarización de Bogotá. Semana, recuperado de http://www.semana.com/nacion/articulo/ santos-ordena-militarizacion-bogota/355743-3

Semana. (1. ${ }^{\circ}$ de septiembre de 2013 d). Indígenas de Nariño levantan paro. Semana, recuperado de http://www.semana.com/nacion/articulo/ indigenas-narino-levantan-paro/356202-3

Semana. (9 de septiembre de 2013e). Los acuerdos para levantar el paro. Semana, recuperado de http://www.semana.com/nacion/articulo/ se-levanta-el-paro-agrario/357014-3

Semana. (3 de diciembre de 2013f). La marcha de los campesinos. Semana, recuperado de http://www.semana.com/nacion/articulo/ marcha-de-campesinos-bogota-dignidad-campesina/366917-3

Semana. (7 de septiembre de 2013g). El general Rodolfo Palomino, director de la Policía, habla de la violencia de las protestas, las Bacrim y la seguridad. Semana. Recuperado de http://www.semana.com/nacion/articulo/ las-evidencias-muestran-que-los-vandalos-son-de-las-farc/356785-3

Semana. (23 de agosto de 2013h). Golpiza del Esmad a un campesino. Semana, recuperado de http://www.semana.com/nacion/articulo/ la-golpiza-del-esmad-campesino-video/355013-3

Semana. (30 de agosto de 2013i). Las 48 personas que buscan tras los disturbios. Semana, recuperado de http://www.semana.com/nacion/articulo/ las-48-personas-buscan-tras-disturbios/355748-3

Smelser, N. (1995). Teoría del comportamiento colectivo. México, D. F.: FCE.

Snow, D. y Benford, R. (1992). Master frames and cycles of protest. En A. Morris y C. McClury (eds.), Frontiers in social movement theory (pp. 133-155). New Haven y Londres: Yale University Press.

Suhner, S. (2002). Resistiendo al olvido. Tendencias recientes del movimiento social y de las organizaciones campesinas en Colombia. Bogotá: Taurus UNRISD.

Tarrow, S. (1997). El poder en movimiento. Los movimientos sociales, la acción colectiva y la política. Madrid: Alianza.

Touraine, A. (1987). El regreso del actor. Buenos Aires: Eudeba.

Wallerstein, I. (2008). Historia y dilemas de los movimientos antisistémicos. Bogotá: Desde Abajo. 
Zald, M. (1999). Cultura, ideología y creación de marcos estratégicos. En D. McAdam, J. McCarthy y M. Zald (eds.), Movimientos sociales: perspectivas comparadas. Oportunidades políticas, estructuras de movilización y marcos interpretativos culturales (pp. 369-388). Madrid: Itsmo.

Zibechi, R. (2006). Dispersar el poder. Buenos Aires: Tinta Limón. 